\title{
Dupuytren's disease in epilepsy: result of prolonged administration of anticonvulsants
}

\author{
E. M. R. CRITCHLEY ${ }^{1}$, S. D. VAKIL, H. W. HAYWARD, AND V. M. H. OWEN \\ From the Preston Royal Infirmary, Preston, Lancashire \\ and Langho Centre, Blackburn, Lancashire
}

SYNOPSIS In a study of chronic epileptics in a residential centre we recorded a $56 \%$ incidence of Dupuytren's disease. The lesions were usually bilateral and symmetrical and frequently associated with knuckle pads and plantar nodules. There was no direct relationship between Dupuytren's disease and frozen shoulder. Dupuytren's disease was seen equally in those with idiopathic or symptomatic epilepsy. The incidence increased with the duration of epilepsy and is probably a sequel to long-term administration of phenobarbitone. Reasons are given for presuming that the association between Dupuytren's disease and antiepileptic therapy is mediated through the peripheral stimulation of tissue growth factors and not through the central release of growth hormone or through alterations in liver metabolism.

During the past decade the haematological and biochemical complications of long-term anticonvulsant therapy have been well documented. Morphological changes consequent upon the medical control of epilepsy have not received similar attention. Early studies by Féré (1890) and Féré and Francillon (1902) on the fingers and palmar aponeuroses of epileptics had not shown any connection between epilepsy and Dupuytren's disease. However, Lund (1941) reported a high incidence of Dupuytren's contracture in epilepsy. Scandinavian neurologists (Ask Upmark, 1944; Skoog, 1948; Lövgren, 1948) have confirmed Lund's observations, ascribing the presence of contractions, knuckle pads, and palmar and plantar nodules to the prolonged administration of phenobarbitone. Over the past 25 years other anticonvulsants have been introduced alongside phenobarbitone. We have therefore attempted a reappraisal of earlier observations, relating the incidence of Dupuytren's disease to current antiepileptic medication, with particular reference to aetiological factors and the biochemical consequences of prolonged therapy.

${ }^{1}$ Address for reprint requests: E. M. R. Critchley, Preston Royal Infirmary, Preston PR1 6PS.

(Accepted 30 December 1975.)
Dupuytren's disease includes two types of lesions involving the palmar fascia between the skin and the palmar aponeurosis. Irregularo fibrosis with mitoses and many cells but littleco collagen produces palmar nodules often adherent? to skin or to subcutaneous fat. Elsewhere, the formation of bands of dense laminated collagen overlying the aponeurosis can result in permanent retraction of the fingers (Dupuytren's contraction or contracture). Nodules and bands are found separately or in combination (Nézelof, 1974) and may be associated with knuckle pads, plantar nodules (Ledderhose disease), or, more rarely, with other thickenings of subcutaneous fascia.

\section{METHODS}

In a redocumentation of residents with epilepsy, a high incidence of Dupuytren's disease was found among the epileptic population. The clinical examination was followed by a photographic study which accentuated the clinical impression of a coarsening of facial and other features among many residents. It seemed possible that Dupuytren's disease was part of a spectrum of facial overgrowth. Among the residents were five whose appearance simulated acromegaly and three gigantism. They were selected 
for special investigation, although there was no radiological evidence of enlargement of pituitary fossae.

\section{RESULTS}

INCIDENCE In a population of chronic epileptics, $57 \%$ of 143 males and $56 \%$ of 218 females were found to have palmar nodules or bands. Bilateral palmar lesions were seen in $70 \%$ of affected males and $60 \%$ of affected females. Where unilateral lesions were present, the left hand was involved more often than the right in the ratio 2:1. Plantar nodules were also present in $30 \%$ of affected individuals. Knuckle pads were found in $42 \%$ of males and $40 \%$ of females, not necessarily in association with palmar lesions. Only 14 residents (3.9\% of the total) had unilateral frozen shoulder: the association, where it did occur with Dupuytren's disease, appeared to be fortuitous.

There was no association between the varied aetiologies of epilepsy-that is, the inherited, or cryptogenic, or secondary varieties-and the occurrence of Dupuytren's disease. Thus, of 177 residents with Dupuytren's disease, $62(35 \%)$ had a documented history of a possible acquired cause for the onset of their convulsions. Nor was there an association between the type of epilepsy as determined by the electroencephalogram and the incidence of Dupuytren's disease. In particular, there was no essential difference in the observed incidence of Dupuytren's disease in residents with focal or non-focal EEG disturbances, or again when those with EEG patterns of petit mal or atypical petit mal were separately considered $(P=0.5)$.

FIT FREQUENCY AND SEVERITY To compare the incidence of Dupuytren's disease with the severity of epilepsy, we examined in the first instance those who had a previous history of status epilepticus. Of 50 residents who had had status epilepticus, 26 had Dupuytren's disease and 24 were unaffected, giving an incidence of $52 \%$ compared with $56 \%$ for the total population. To study the relationship of Dupuytren's disease with fit frequency, the incidence of fits was estimated over a three year period and a comparison made between those having daily, weekly, monthly, and yearly attacks and those without recent fits. A negative correlation was found between fit frequency and the percentage with Dupuytren's disease. Routine EEGs were then graded relative to the severity of dysrhythmia. Severe suggested that the fits were out of control or poorly controlled, moderate that the diagnosis of epilepsy could readily be made from the EEG alone, mild that other supportive evidence would be required, and a small group were within normal limits. After making allowance for alterations in the severity of the EEG pattern with age, no definite trend emerges.

A definite correlation $(\mathrm{P}=0.01)$ was seen between the occurrence of Dupuytren's disease and the duration of fits and/or of treatment (Fig. 1). After 20 years there is a greater than $50 \%$ chance of a male developing Dupuytren's disease and after 30 years of a female developing the condition. The incidence thereafter rises irrespective of sex.

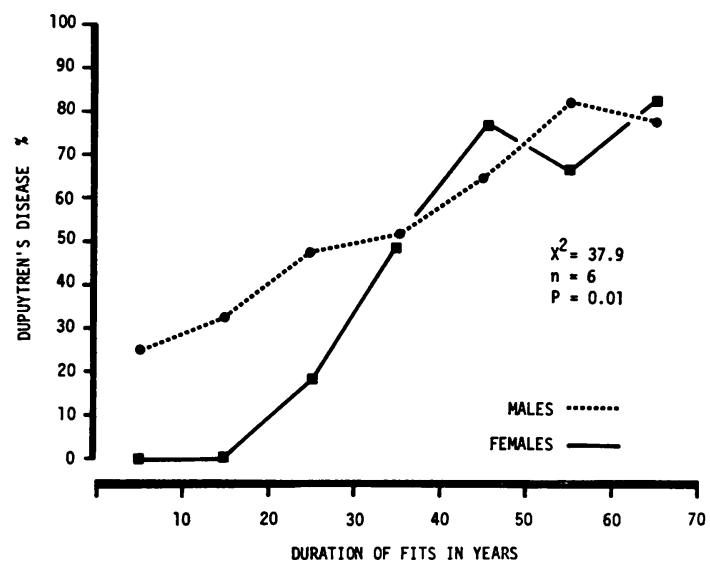

FIG. 1 Incidence of Dupuytren's disease and the duration of fits.

TYPES OF ANTICONVULSANT The types of anticonvulsant medication taken, either together or sequentially, were analysed. Forty-one residents had received only one drug, 69 a combination of two drugs, 100 three drugs, and 76 four or more anticonvulsants. No correlation was found between the dosage, the number of different anticonvulsants used, and the percentage with Dupuytren's disease (Figs. 2 and 3). A satisfactory comparison could not be made between those taking a single drug, as 33 out of 40 had taken phenobarbitone as the sole medication and only seven had received other antiepileptic drugs. 


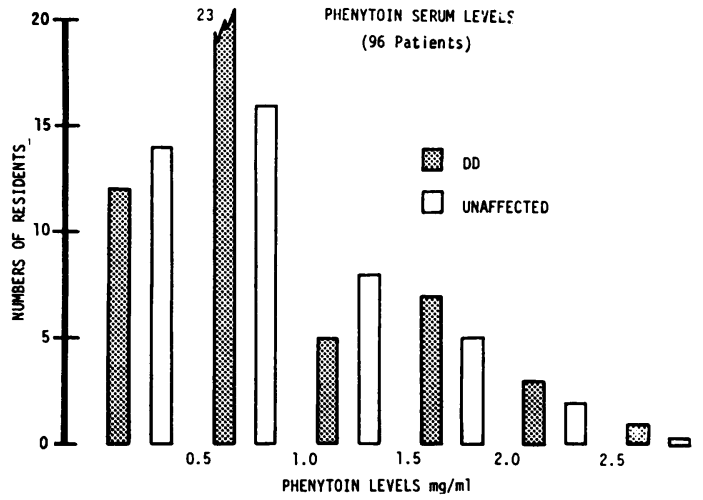

FIG. 2 Incidence of Dupuytren's disease $(D D)$ in epileptics with different serum levels of phenytoin.

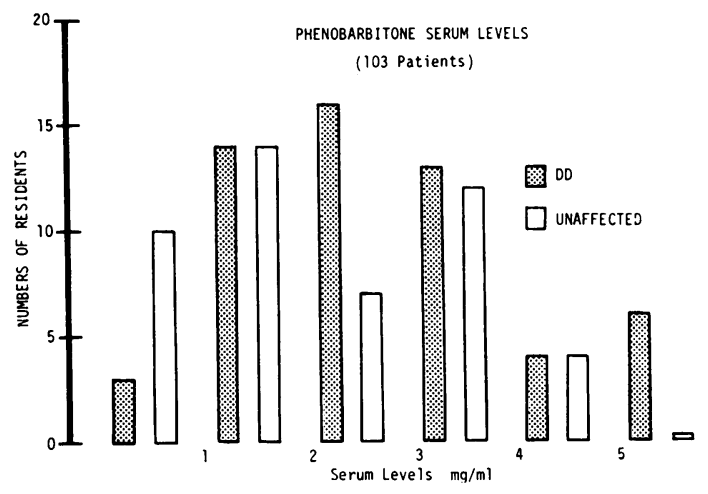

FIG 3. Incidence of Dupuytren's disease $(D D)$ in epileptics with different serum levels of phenobarbitone.

TABLE

HAEMATOLOGICAL AND BIOCHEMICAL INDICES
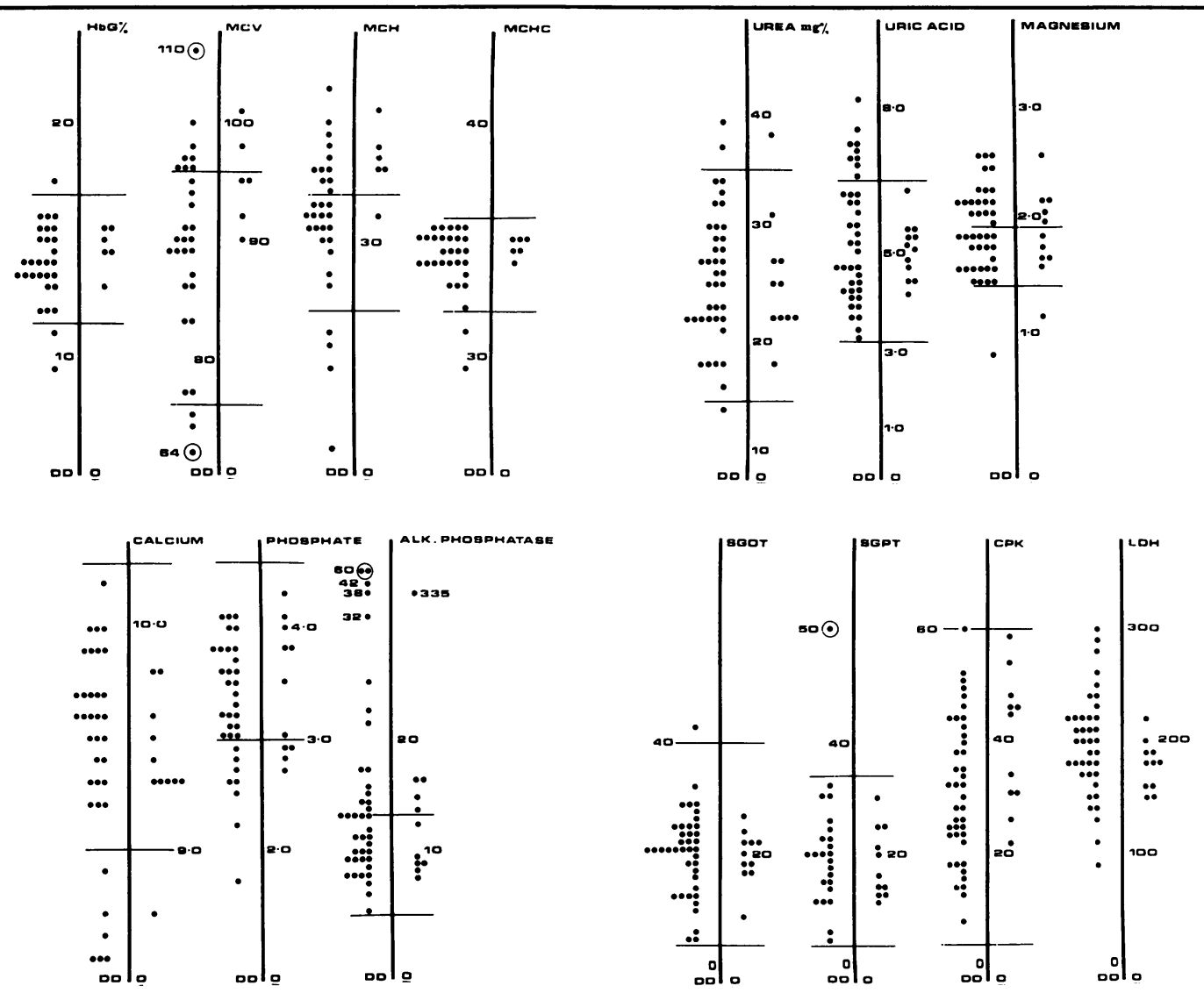

Subjects with Dupuytren's disease are shown to the left of the vertical lines, unaffected subjects to the right. The normal range for each parameter is shown between the horizontal lines. 
When two-drug combinations were analysed, those taking combinations limited to phenobarbitone, phenytoin, or primidone showed a high incidence of Dupuytren's disease $(66 \%$ to $69 \%$ ), whereas those who had received a newer drug in combination showed a lesser incidence. The observed difference could be related to the fact that the newer anticonvulsants had been administered over a shorter period.

However, if those on phenobarbitone are excluded from consideration, the risk of acquiring Dupuytren's disease falls dramatically. Only two out of 21 not receiving phenobarbitone had evidence of Dupuytren's disease. These two, a female aged 43 and a male aged 54 years, were both taking primidone, of which phenobarbitone is a major metabolite.

BIOCHEMICAL CHANGES The biochemical and haematological abnormalities in our epileptic population are similar to those previously described. In the Table, our findings have been divided to separate those residents with Dupuytren's disease and those without. There was no observable association or trend connecting any particular abnormality with Dupuytren's disease.

To examine for abnormalities in release of growth hormone glucose tolerance tests with simultaneous growth hormone estimations were performed in 16 residents, eight of whom had severe bilateral palmar lesions with knuckle pads and plantar involvement, and eight had features simulating acromegaly or gigantism. The highest fasting blood level was $6 \mathrm{ng} / \mathrm{ml}$ and the highest three-hour level (in a tall female aged 29 years) was $23 \mathrm{ng} / \mathrm{ml}$. The majority of those tested showed little fluctuation, remaining between 0.4 and $2 \mathrm{ng} / \mathrm{ml}$.

\section{DISCUSSION}

Our studies confirm and extend earlier observations on the association of Dupuytren's disease and epilepsy (Fig. 4). Lund (1941) had found an incidence of $50 \%$ among 190 males and $25 \%$ among 171 female epileptics and Thieme (1968) found an overall incidence of $36.9 \%$. Early (1962) compared the incidence of Dupuytren's contracture in the general population of the town of Leigh, among engineers in a locomotive workshop at Crewe, and the residents of the David Lewis

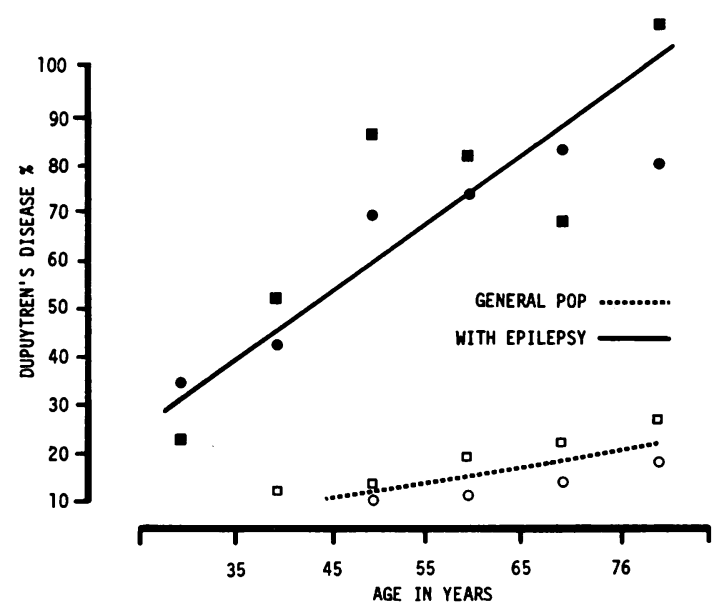

FIG. 4 The incidence found in the Epileptic Centre is compared with that of the town of Leigh, 30 miles away, studied by Early (1962).

Centre for Epilepsy. In non-epileptic populations the incidence of Dupuytren's contracture ranged from $1 \%$ in the $35-44$ years age group to $18 \%$ over 75 years of age for men and for women from $0.5 \%$ at $45-54$ years to $9 \%$ over 75 years.

Two of Early's observations are confirmed in the present study: the common association with knuckle pads and plantar nodules, and the tendency for Dupuytren's disease in epileptics to be bilateral and symmetrical. Early (1962) included frozen shoulder (periarthritis of the shoulder) as part of the disease diathesis. In our series, the condition was but rarely associated with Dupuytren's disease and was usually a sequel to a long standing hemiparesis.

In Skoog's series (1948), the frequent occurrence of 'hand deformity' was seen in epileptic patients, irrespective of the aetiology of their epilepsy. Ling (1963) collected pedigrees from the general population exhibiting a dominant mode of inheritance of Dupuytren's disease; and James (1969) argued that epilepsy and Dupuytren's disease are both genetically determined and represent linked dominant genes. Our findings refute James's contention and support the observations made by Skoog (1948). Dupuytren's disease occurs in all types of epilepsy of long standing.

The high incidence of Dupuytren's disease in modern series is in direct contrast with Féré's observations $(1890,1902)$ at the turn of the 
century. He was interested in the palmar aponeurosis and had made an ergometric study of the fingers of 134 epileptics. In the course of his writings, he mentions only one example of Dupuytren's disease among epileptics. Thus it would seem, as asserted by Lund (1941), that Dupuytren's disease is a relatively new symptom in epilepsy and that the administration of phenobarbitone might be of significance. Skoog (1948) found no relationship with the age of onset of epilepsy or with the frequency of fits but observed that the frequency of contraction increased with the duration of epilepsy. These observations, confirmed in the present series, do not explain the connection between phenobarbitone therapy and the occurrence of Dupuytren's disease. Pöjer et al. (1972) claimed that the associationas between that of Dupuytren's disease and alcoholism-was a result of abnormal liver function. They studied 65 epileptics of long standing, $36(55 \%)$ of whom were found to have Dupuytren's disease. The mean age of the epileptics with Dupuytren's disease was 51 years, compared with 40 years for those without Dupuytren's disease. They found a significant association of Dupuytren's disease, elevated alkaline phosphatase, leucine aminopeptidase, and (among men only) serum glutamic pyruvate transaminase and creatine phosphokinase in the absence of hepatomegaly or previous liver disease. The values obtained were less significant when age-related factors were considered. We were unable to confirm their observations. Among the epileptics we studied, a third showed an elevated alkaline phosphatase and a few an increase above normal of aspartate transaminase (SGOT) and alanine transaminase (SGPT). The values for creatinine phosphokinase and lactic dehydrogenase were within normal limits. There was no difference between those with and those without Dupuytren's disease.

An alternative hypothesis which might explain the association of phenobarbitone administration and Dupuytren's disease involves the mediation of tissue growth factors. Such a possibility was suggested clinically by the observation of Ghosh and McCandless (1975) that acceleration of growth is apparent in children with temporal lobe epilepsy, with a tendency for those with petit mal to be smaller than average; and by the fact that phenobarbitone can affect release of corti- cotrophin (Hedner and Rerup, 1960), gonadotrophin (Everrett and Sawyer, 1950), and antidiuretic hormone (de Bodo and Prescott, 1945), We were unable to find any abnormal fluctuation of release of growth hormone during glucose tolerance tests which might have suggested a central disturbance involving tissue growth, and therefore we presume that the action of anticonvulsants is a direct one upon the peripheral tissues.

We wish to thank the staff and residents of Langho Centre, the Biochemistry Department of Blackburn Royal Infirmary, the Departments of Neuro-electrophysiology and Medical Illustration of Preston Royal Infirmary, and Dr Derek Davies and Mr I. Laing, Ph.D., of the Department of Endocrinology, Manchester Royal Infirmary. The work was done as part of a DHSS grant to Langho Centre and the photographic study was supported by a grant from Preston Royal Infirmary Research Fund. We also thank Miss G. Gorton for typing the manuscript.

\section{REFERENCES}

Ask Upmark, E. (1944). Năgra korrelationer mellan hjärta och arn. Nordisk Medicin, 21, 434-436.

de Bodo, R. C., and Prescott, K. F. (1945). The antidiuretic action of barbiturates (phenobarbital, amytal, pentobarbital) and the mechanism involved in this action. Journal of Pharmacology and Experimental Therapeutics, 85, 222-233.

Early, P. F. (1962). Population studies in Dupuytren's contracture. Journal of Bone and Joint Surgery, 44B, 602-613.

Everrett, J. W., and Sawyer, C. H. (1950). A 24-hour periodicity in the ' $\mathrm{LH}$ release apparatus' of female rats, disclosed by barbiturate sodium. Endocrinology, 47, 198-218.

Féré, C. (1890). Les Épilepsies et les Épileptiques. Ancienne Librairie Gerner Baillière, Felix Alcan: Paris.

Féré, C., and Francillon, M. (1902). Note sur le fréquence de la retraction de l'aponeurose palmaire. Revue Médecine, 22, 539-551.

Ghosh, A., and McCandless, A. E. (1975). Growth and anticonvulsant therapy. Lancet, 1, 858-859.

Hedner, P., and Rerup, C. (1960). The effect of pentobarbital (Membunal NFN) and ether anesthesia on the content of corticotrophin in the pituitary glands of three animal species. Acta Pharmacology and Toxicology, $K b h, 16,223-228$.

James, J. I. P. (1969). The relationship of Dupuytren's contracture and epilepsy. Hand. 1, 47-49.

Ling, R. S. M. (1963). The genetic factor in Dupuytren's disease. Journal of Bone and Joint Surgery, 45B, 709-718. 
Lövgren, O.(1948). Dupuytren's contracture and epilepsy, om.S.K. barbitursyrereumetism. Svenska Lakartidningen, 45/6, 234-236.

Lund, M. (1941). Dupuytren's contracture and epilepsy. Acta Psychiatrica et Neurologica, 16, 465-492.

Nézelof, C. (1974). Histological aspects of Dupuytren's contracture. Dupuytren's Disease, 2nd edn. Edited by J. T. Hueston and R. Tubiana. Churchill: London.

Pöjer, J., Radwojevic, M., and Williams, J. F. (1972).
Dupuytren's disease. Its association with abnormal liver function in alcoholism and epilepsy. Archives of Internal Medicine, 129, 561-566.

Skoog, T. (1948). Dupuytren's contracture with special reference to aetiology and improved surgical treatment. Its occurrence in epileptics. Note on knuckle pads. Acta Chirurgica Scandinavica, 96, suppl. 139.

Thieme, W. T. (1968). Incidence of Dupuytren's contracture in Edinburgh. Journal of Bone and Joint Surgery, 52B, 14-28. 